\title{
Optimization of Chitosan Drying Temperature on The Quality and Quantity of Edible Film
}

\author{
Endah Sri Wahyuni ${ }^{1}$ and Fahmi Arifan ${ }^{1, *}$ \\ ${ }^{1}$ Chemical Engineering, Diponegoro University, Semarang, Indonesia
}

\begin{abstract}
Edible film is a thin layer (biodegradable) used to coat food and can be eaten. In addition edible film serves as a vapor transfer inhibitor, inhibits gas exchange, prevents aroma loss, prevents fat transfer, improves physical characteristics, and as an additive carrier. Edible film made of cassava starch, glycerol and chitosan. Cassava starch is used as raw material because it contains $80 \%$ starch. Glycerol serves as a plasticizer and chitosan serves to form films and membranes well. The purpose of this research is to know the characteristic test of edible film by using ANOVA analys is, where the variable of drying of the oven is temperature $\left(70^{\circ} \mathrm{C}, 80^{\circ} \mathrm{C}, 90^{\circ} \mathrm{C}\right)$ and time for 3 hours and variables change chitosan $(2 \mathrm{gr}, 3 \mathrm{gr}, 4 \mathrm{gr})$. The result of this research was obtained the most optimum for water content and water resistance in temperature variable $80{ }^{\circ} \mathrm{C}$ and chitosan 4 gr. The best edible films and bubbles on temperature variables are $80{ }^{\circ} \mathrm{C}$ and chitosan 4 gr.
\end{abstract}

\section{Introduction}

Foodstuffs are generally very sensitive and susceptible to quality degradation due to environmental, chemical, biochemical and microbiological factors. Decrease in quality can be accelerated in the presence of oxygen, water, light, and temperature. One way to prevent or slow the phenomenon is with proper packaging [1].

Plastic packaging materials are widely used with economic consideration and provide good protection in preservation. About $60 \%$ of polyethylene and $27 \%$ of polyester are produced to make packaging materials used in food products. However, the use of synthetic materials has an impact on environmental pollution [2]. Therefore, at this time research is needed on packaging materials that can be described (biodegradable) [2,3].

The development of edible films on food in addition to providing better product quality and extended durability, can also be an environmentally friendly packaging material. Edible film provides an alternative packing material that has no impact on environmental pollution because it uses renewable materials and is cheap [4-6]. The application of edible films on food products is not a new concept and has been extensively studied extensively. The application of edible films can extend the shelf life and maintain the quality of various food products $[5,6]$.

Polysaccharides such as starch can be used as raw material for edible film making. Starches are often used in the food industry as biodegradable films to replace plastic polymers because they are economical, renewable, and provide good physical characteristics [4]. Cassava starch is often used as a supplementary ingredient in the food industry and starch-based industry due to its high stone content $[7,8]$. High starch production, easy planting, and easy to find in Indonesia make cassava potential to be used as the basic material of edible film [9].

This study aims to produce quality edible film, both physically and chemically, this research tries to use temperature and chitosan variation on edible film drying of cassava starch and to study the influence of each factor on the measured parameter.

\section{Methods}

The experiment were conducted on March 2017 in Chemical Lab in Chemical Engineering Diponegoro University.

\subsection{Raw Material}

\subsubsection{Starch solution}

Edible film obtained from the main ingredient of starch flour. 6 gr starch flour plus $100 \mathrm{ml}$ aquadest in $1000 \mathrm{ml}$ beaker glass. Mix starch and water flour on magnetic stirrer for 10 minutes at room temperature to form a starch suspension. The resulting suspension is stirred and heated at $60^{\circ} \mathrm{C}$ for 15 minutes with a stirring scale of 6 to form a starch gel.

\subsubsection{Chitosan solution}

Chitosan variable 2, 3, 4 gr plus $100 \mathrm{ml}$ of $1 \%$ acetic acid concentration in beaker glass $500 \mathrm{ml}$. Mix both materials on magnetic stirrer with temperature $50^{\circ} \mathrm{C}$ for 20 minutes with stirring scale 6 . Formed yellow light chitosan gel. 


\subsection{Edible film Preparation}

Edible film, starch gel mixed with chitosan gel. Then stirred and reheated at $60^{\circ} \mathrm{C}$ for 20 minutes. At 10 minutes added $4 \mathrm{ml}$ of glycerol. Stirring is resumed until the solution is completely mixed ( \pm 15 minutes). Edible Solution The resulting film, removed its impurities and bubbles, then settled momentarily at room temperature. Set up a $20 \times 5 \mathrm{~cm}$ glass plate that has been cleaned and taped. Edible film solution is poured in glass plate slowly evenly. The glass plate along with the edible film is dried in an oven with variable temperature $\left(70^{\circ} \mathrm{C}\right.$, $80^{\circ} \mathrm{C}, 90^{\circ} \mathrm{C}$ ) for 3 hours. The dried film is released from the glass plate. Edible film formation of cassava starch and shrimp chitosan with the addition of glycerol plasticizer

\subsection{Water Content Analysis}

Determination of water content in food can be done by drying method (with regular oven), where calculation of moisture content based on dry matter (dry base). Dry base is the ratio between the weight of the water in the material and its dry weight. Dry matter is the weight of the original material after being reduced by the weight of the water [10].

$$
\% \text { Water content }=\frac{(\text { initial initial }- \text { weight weight })}{(\text { final weight })} \times 100 \%
$$

\subsection{Water Resistance Analysis}

The water resistance test procedure is by weighing the initial weight of the sample to be tested (wo), then inserted into a container containing the distilled water for 10 seconds. The sample is removed from the container containing the distilled water and the water contained on the plastic surface is removed with a paper tissue, after which the weighing is done. Samples are put back into the container containing the distilled water for 10 seconds. Then the sample is removed from the container and recalculated. The weighing is repeated until the final sample weight is obtained [11]. Furthermore the water absorbed by the sample is calculated through the equation:

$$
\text { water }(\%)=\frac{W-W_{0}}{W_{0}} \times 100 \%
$$

\subsection{Organoleptic Analysis}

Organoleptic analysis or sense-test is a way of testing using the human senses as the primary means of measuring the reception power of the product. Organoleptic testing has an important role in the application of material quality. Organoleptic test ie product color analysis and bubble analysis

\section{Results and Discussion}

\subsection{Water Content Analysis}

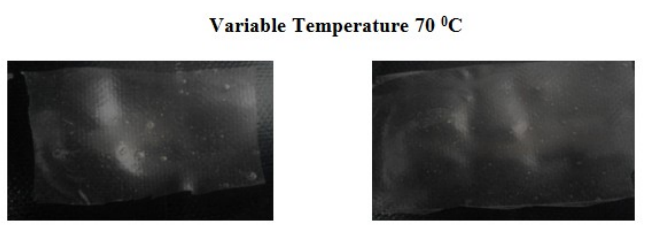

Chitosan 2 gr

Chitosan 3 gr

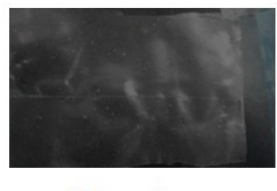

Chitosan 4 gr

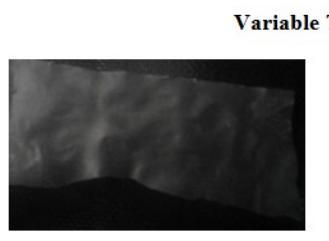

Chitosan 2 gr

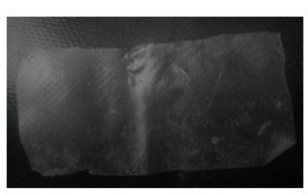

Chitosan $4 \mathrm{gr}$

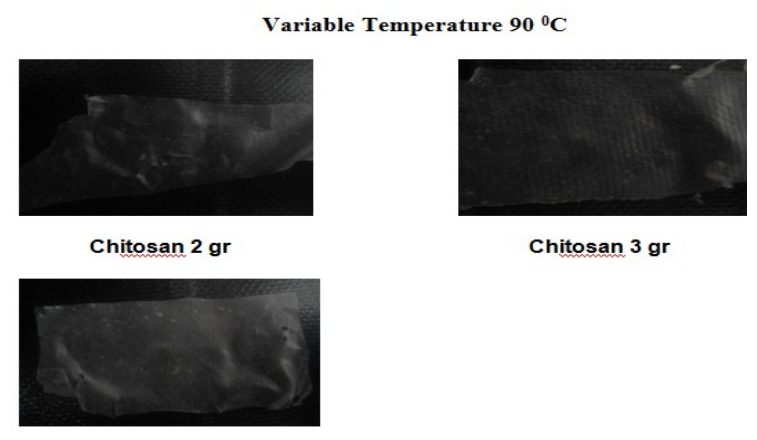

Chitosan 4 gr
Fig. 1. Edible film in the temperature variable $700 \mathrm{C}, 800 \mathrm{C}$, 900C.

Water content based on dry matter (dry basis is the ratio of the weight of water in the material to dry weight Dry material is the weight of the original material after it is reduced by the weight of the water.

This water content analysis was performed by using 3 gram samples from each of the oven variables with temperature of $1050 \mathrm{C}$ for 15 minutes. 
Table 1. Water content analys is edible film

\begin{tabular}{cccccc}
\hline \multirow{2}{*}{ Variable } & Temperature & Time & \multicolumn{3}{c}{ Water content(\%) } \\
\cline { 5 - 6 } & $\left({ }^{0} \mathrm{C}\right)$ & (hours) & A & $\mathrm{B}$ & $\mathrm{C}$ \\
\hline 1 & 70 & 3 & $34,3 \%$ & $25,3 \%$ & $21,7 \%$ \\
2 & 80 & 3 & $19 \%$ & $14 \%$ & $13,3 \%$ \\
3 & 90 & 3 & $10,7 \%$ & $9 \%$ & $7,3 \%$ \\
\hline
\end{tabular}

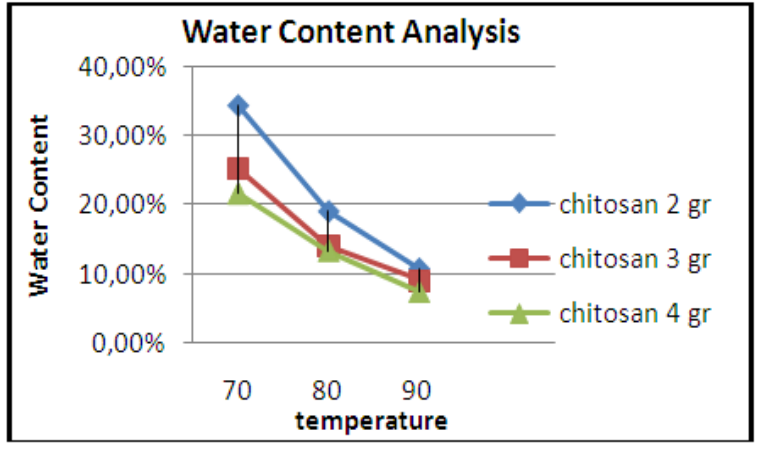

Fig 2. Water Content Analysis

Based on fig 2 of the water content analysis tendency to decrease the edible water content of the film along with the increase of added chitosan concentration. This is due to the hydrophobic nature of chitosan. Hydrophobic is the inability of a compound to bind water, so edible film with the addition of higher chitosan causes the water content in the material to decrease and the resulting water content becomes low $[11,12]$. In addition, the use of starch as a base material in the manufacture of edible film causes the resulting film has high water content so that the edible film added khitosan with low concentration causes the water content increases, as in the variables with the addition of chitosan 2 gr and 3 gr. This happens because the starch has the ability to absorb water because it has a hydroxyl group. The starch molecule contains a very large hydroxyl group so the ability to absorb water is also very large. This supports that with the addition of chitosan with high concentration will produce edible film with a small water content [13].

Based on the theory above the most appropriate water content is a temperature variable of $800 \mathrm{C}$ with the addition of chitosan $4 \mathrm{gr}$ is obtained water content of $13.3 \%$. With the water content is produced edible films that are not dry only so not fragile and not moist, other than that high water content susceptible to microbial growth.

\subsection{Water resistance analysis}

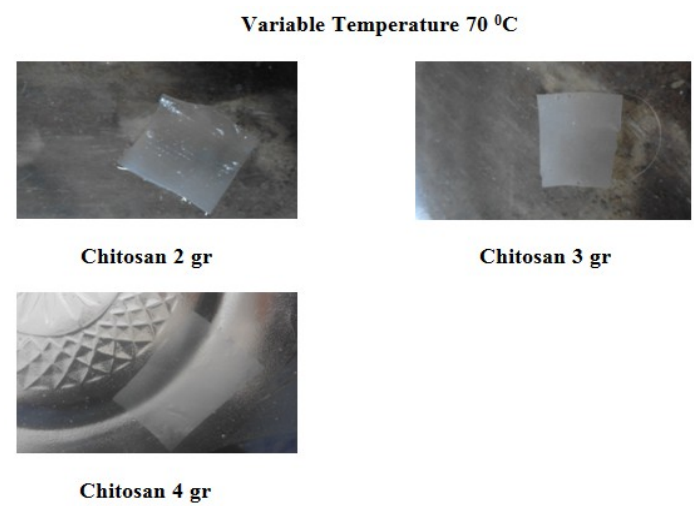

Variable Temperature $80^{\circ} \mathrm{C}$
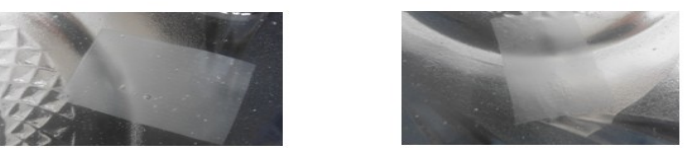

Chitosan 2 gr

Chitosan 3 gr

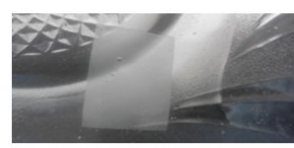

Chitosan 4 gr

Variable Temperature $90{ }^{\circ} \mathrm{C}$

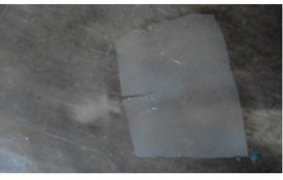

Chitosan 2 gr|

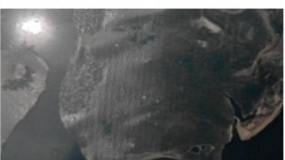

Chitosan $4 \mathrm{gr}$

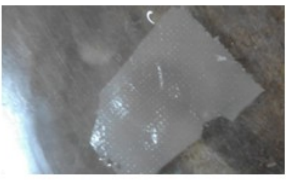

Chitosan 3 gr
Fig. 2. Edible film in the temperature variable $700 \mathrm{C}, 800 \mathrm{C}$, 900C. 
Table 2. Results of Resilience to Water edible film

\begin{tabular}{cccccc}
\hline \multirow{2}{*}{ Variable } & Temperature & Time & & \multicolumn{3}{c}{ Water res istance } \\
\cline { 5 - 7 } & $\left({ }^{0} \mathrm{C}\right)$ & (hours) & $\mathrm{A}$ & $\mathrm{B}$ & $\mathrm{C}$ \\
\hline 1 & 70 & 3 & $17,4 \%$ & $18,2 \%$ & $16,9 \%$ \\
2 & 80 & 3 & $17,86 \%$ & $17,6 \%$ & $16,4 \%$ \\
3 & 90 & 3 & $17,72 \%$ & $15,49 \%$ & $15,28 \%$ \\
\hline
\end{tabular}

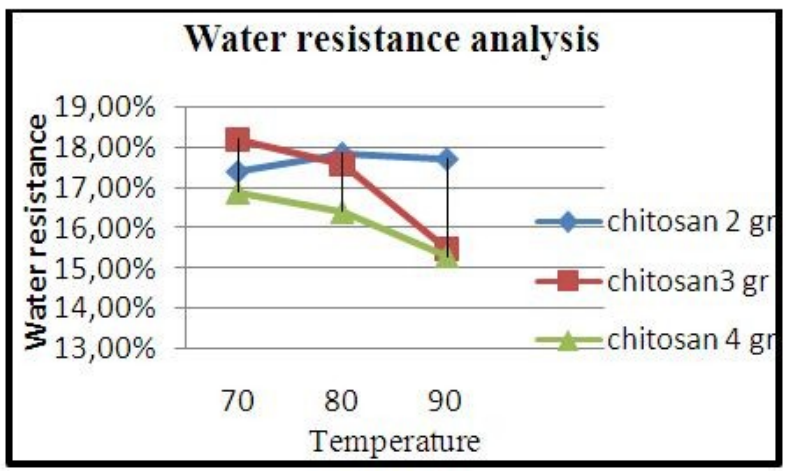

Graph 2. Water resistance analys is

Edible resistance of film to water can be done using swelling test. Swelling is the ability of a polymer to absorb the solvent and experience a certain volume swelling. The water resistance test in this study was conducted with edible sample size of $1 \times 2 \mathrm{~cm}$ where weighing the initial weight of the sample to be tested (wo), then inserted into the container containing the distilled water for 10 seconds. The immersion and weighing procedure is repeated until the final sample weight is obtained constantly.

The value of water resistance in the film is said to be good if the percent swelling is low. So the lower percent swelling that is obtained then the resulting film more water resistant. In general there is a tendency to decrease the sweeling value of the edible film as the added concentration of chitosan is added. The higher the concentration of added chitosan, the smaller the swelling percentage [4]. This is because the nature of chitosan is hydrophobic (do not like water). Chitosan has insoluble properties in water and organic solvents because chitosan has a crystal structure composed of intramolecular and intermolucular hydrogen bonds [14,15].According to Muzarelli et al, [15] stated that chitosan has a negatively charged hydroxyl group (-OH) and an amin (-NH2) group that is positively charged so that the chitosan is able to bind strongly ionic. The presence of negatively charged hydroxyl groups on chitosan causes chitosan to be hydrophobic and has an effect in increasing the percentage of water resistance of edible film produced.

Based on the water resistance test, the best result is the temperature variable of $800 \mathrm{C}$ with the addition of chitosan 4 gr that is obtained $\%$ water resistance of 0,164 With\% water resistance is produced edible film that absorbs water with small quantities and not destroyed when the swelling test.

\subsection{Organoleptic Analysis}

Table 3. Organoleptic Analysis Edible Film

\begin{tabular}{|c|c|c|c|c|c|c|}
\hline \multirow{2}{*}{ Variable } & \multicolumn{3}{|c|}{ Color } & \multicolumn{3}{|c|}{ Bubble } \\
\hline & A & B & C & A & B & $\mathrm{C}$ \\
\hline 1 & Brown & Brown & Brown & Many & Little & Little \\
\hline 2 & $\begin{array}{c}\text { Transparent } \\
\text { white }\end{array}$ & $\begin{array}{c}\text { Transparent } \\
\text { white }\end{array}$ & $\begin{array}{c}\text { Transparent } \\
\text { white }\end{array}$ & Little & Little & - \\
\hline 3 & $\begin{array}{c}\text { Transparent } \\
\text { white }\end{array}$ & $\begin{array}{c}\text { Transparent } \\
\text { white }\end{array}$ & $\begin{array}{c}\text { Transparent } \\
\text { white }\end{array}$ & Little & - & - \\
\hline
\end{tabular}

The color of the edible film is determined by the visual (subjective) test. Factors affecting the color of the edible film is the drying temperature. The most optimum color is the temperature variable $80^{\circ} \mathrm{C}$ and 3 hours of drying time is transparent white. While at the temperature of $70^{\circ} \mathrm{C}$ and the duration of drying 3 hours of brownish white edible film this may be due to the temperature is less hot so that the film is still thick and the color can not be transparent.

The number of air bubbles means the worse the quality of edible film because the more air bubbles the worse the water resistance of edible film. The number of air bubbles caused by the process of formation of cassava starch gelatin is not perfect.

\section{Conclusion}

The most optimum variable on water content analysis and water resistance is temperature of $800 \mathrm{C}$ with the addition of chitosan 4 gr that is got water content equal to $13,3 \%$. And water resistance of $16.4 \%$. Organoleptic analysis on edible film obtained results include color and bubbles, where the most optimal result is on the temperature variable $800 \mathrm{C}$ and 3 hours of drying time is transparent white and no bubbles. The number of air bubbles means the worse the quality of edible film because the more air bubbles the worse the water resistance of edible film.

\section{Acknowledgement}

The authors acknowledge with gratitude the support given by Diponegoro University for our research in this area. 


\section{References}

1. Y. H. Hui, Handbook of Food Science, Technology, and Engineering Volume II CRC Press, USA, (2006)

2. Henrique, C. M., R. F. Teofilo, L. Sabino, M. M. C. Ferreira, and M. P. Cereda, Journal of Food Science. 74: E184-E189, (2007)

3. S. Kittur, K.R. Kumar and R.N. Tharanathan, Functional packaging properties of chitosan film. Z. Lebesm Unters Forsch A. 206, (1998)

4. T. Bourtoom, 2007. Effect of Some Process Parameters on The Properties of Edible Movie Prepared From Starch. Department of Material Product Technology, Songkhala. (On line) Avaliable at: http://vishnu.sut.ac.

5. M. C. Chen, G. H. C. Yeh, B. H. Chiang, J. Food Processing and Preservation 20: 379-390, (1996)

6. W.S Subowo, and S. Pujiastuti, Proceedings of National Symposium of Polymers IV, Bandung, Center for Informatics Research-LIPI, pp. 203208, (2003)

7. Susilawati, Biodegradable Plastics From A Mixture Of low density Polyethylene.http: //download.portalgaruda.org, (2011)

8. Vendy, Utilization of Cassava Starch As Raw Material.http: //.uns.ac.id, (2010)
9. Winarno, Biofermentase and Protein Biosynthesis. PT. Space. Bandung, (1992)

10. Wulan, Determination of Water Content Method

Oven.Https://wulaniriky.Wordpress.com, (2011)

11. Hargono, et al. Making Chitosan From Shrimp Shell Waste And Its Application In Reducing Cholesterol Fat Goat.http: //staff.uny.ac.id.

12. Fehragucci, Helmi, Practical Addition of Plasticizer And Chitosan To The Charible Edible Film Ca-Algina. Https://dglib.uns.ac.id, (2012)

13. Puspita, Tyas, Pengaruh Addition Of Khitosan And Plasticizer Glycerol On Biodegradable Plastic Characteristics Of Cassava Skin Waste Starch: http://digilib.its.ac.id, (2012)

14. M. Manullang, Bul. Technology and Food Industry. Vol IX no. 1: 34-43, (1998)

15. Muzarelli, R. A. A. Farsi, R. Filippini, O. Giovanetti, E. Biagini, G. Varaldo, P. E, Antimicrobial Agents Chemonth 34: 20192023, (1990)

16. Chen, C. S. Liau, W. Y. and Tsai, G. J, J. Food Prot 61: 1124-1128 $\therefore$ 44-47, (1998) 